\title{
Estimation of lateral inflows using data assimilation in the context of real-time flood forecasting for the Marne catchment in France
}

\author{
Johan Habert \\ DREAL Champagne-Ardenne, \\ Chalons-en-Champagne, France \\ johan.habert@developpement-durable.gouv.fr
}

Sophie Ricci, Andrea Piacentini, Gabriel Jonville, Thierry Morel, Florent Duchaine, Anthony Thevenin

URA 1875/CERFACS, Toulouse, France ricci@cerfacs.fr, piacentini@cerfacs.fr, jonville@cerfacs.fr, morel@cerfacs.fr, duchaine@cerfacs.fr, thevenin@cerfacs.fr

\begin{abstract}
The present study describes the assimilation of discharge in-situ data for operational flood forecasting. The study was carried out on the Marne river (France) catchment where lateral inflows's uncertainty are important due to karstic areas. This source of error was partly accounted for using an Extended Kalman Filter algorithm built on top on a monodimensional hydraulic model. The Data Assimilation algorithm is achieved using the OpenPALM dynamic coupling software that allows for a computationally efficient implementation.
\end{abstract}

\section{INTRODUCTION}

In 2006, 9\% of the French population was exposed to flood risk, one of the greatest natural risks causing damage and human loss [21]. The French flood forecasting service (SCHAPI - Service Central d'Hydrométéorologie et d'Appui à la Prévision des Inondations), in collaboration with the 22 local flood forecasting centers (SPC- Service de Prévision des Crues) produces a twice-daily broadcast vigilance map available to governemental authorities and general public (http://www.vigicrues.gouv.fr).

In order to effectively support emergency management and decision making it is essential to properly characterize the different sources of uncertainty in hydrologic forecasts [3][25]. The reliability of flood forecasting strongly depends on the quality of the hydraulics model, its boundary conditions (upstream and lateral inflow), hydrological initial conditions and numerical parameters. Much effort has been directed towards the estimation of hydrologic and hydraulic model parameters especially for the statistical analysis of parameters uncertainties usually using a historical batch of data, assuming time-invariant parameters [6][24]. In practice,

\author{
Etienne Le Pape \\ SCHAPI, Toulouse, France \\ Etienne.lepape@developpement-durable.gouv.fr
}

Olivier Thual

URA1875/CERFACS and INPT, CNRS, IMFT, Toulouse thual@imft.fr

\author{
Nicole Goutal, Fabrice Zaoui, Riadh Ata \\ LNHE EDF-R\&D, Chatou, France \\ nicole.goutal@edf.fr, fabrice.zaoui@edf.fr, \\ riadh.ata@edf.fr
}

in addition to model simulation and batch calibration, the reliable operation of a watershed system requires a continuous correction of the forecast as observational data become available [18]. The application of data assimilation (DA) [1], which optimally merges information from model simulations and independent observations with appropriate uncertainty modelling, has proved promising in improving prediction accuracy and quantifying uncertainty [11][13][14][16]. Still, the use of such methods by operational agencies is rare and the need for implementing effective DA in the flood forecast process is increasing when flood frequency is likely to increase as a result of altered precipitation patterns triggered by climate change [5].

DA offers a convenient framework to overcome some of the limits of the calibration processes: observations and simulation outputs are combined to estimate an optimal set of model parameters and consequently reduce uncertainties in the simulation. With the increasing abundance of new in-situ and remote sensing observations, DA was applied in several studies formulated in an operational framework. A great number of implementations were made on top of hydrological models in order to improve soil moisture initial conditions. Thirel et al. (2010a,b) [22][23] assimilated past discharges to obtain a better initial soil moisture state and improve ensemble streamflow simulations. Dechant and Moradkhani (2011a) [4] used SNOTEL data to improve the estimation of snow water storage and consequently improve the ensemble streamflow prediction from the National Weather Service River Forecast System (USA). Seo et al. (2003, 2009) [19][20] explored variational assimilation of hydrologic and hydro-meteorologic data into operational hydrologic forecast. The Kalman Filter (KF) [8] algorithm is the most commonly used sequential DA algorithm which 
results in the optimal estimation for linear dynamic models with Gaussian uncertainties. It was extended to nonlinear problems using a first order approximation of Taylor series, namely Extended Kalman Filter (EKF), or an ensemble approach for the Ensemble Kalman Filter (EnKF) [7]. These algorithms are also now widely being used in hydrology and hydraulics for the estimation of model states [10][12] as well as model parameters [15].

In the context of hydrodynamics modelling, Ricci et al. (2011) [17] showed that the EKF assimilation of water level observations on the Adour catchment with the 1D hydraulic model MASCARET [9] developed by LNHE (Laboratoire National d'Hydraulique et d'environnement) from EDF-R\&D (Electricité De France Recherche et Développement) enabled to improve flood forecasting of $60 \%$ at a one hour lead time and of $25 \%$ at a twelve-hour lead time. In the present study, a similar approach is applied to flood forecasting in the Marne catchment where the presence of karstic areas makes it hard to correctly specify upstream and lateral inflows to the model. In the framework of operational flood forecasting, the SAMA (Seine Amont Marne Amont) SPC has developed two different models on two limited areas of the Marne catchment described in Fig. 1. On these limited areas, the batch calibration of the model was possible and the uncertainties due to lateral inflow were accounted for by artificially adjusting the Strickler coefficients. Still, in order to increase the forecast time on the Marne catchment, both models were recently merged into a global model far more difficult to calibrate. The need for a coherent estimation of the so far neglected inflows, which represent the dynamics of the karstic areas, and the non-modelled tributaries, which represent the dynamics of catchment areas, motivates the use of a DA procedure using in situ measurements. A realistic and time varying estimation of the lateral inflows is then achieved using a sequential data assimilation approach on 10 flood events over 2001-2010. It is shown that, in spite of certain limitations described further on, this approach provides a reliable estimate of the lateral inflows and leads to the improvement of the flood forecast at meaningful lead times for operational use.

The structure of the paper is as follows. Section II provides a description of the Marne catchment. The DA method is described in Section III along with the choices made for the implementation of the algorithm. Section IV gives an overview of the results, highlighting the merits of the approach for flood forecasting along with its limitations on a representative flood event. Conclusions are given in Section V.

\section{MODELLiNG THE MARNE CATCHMENT}

The Marne catchment is a karstic basin located East of the Paris basin. The Marne river is a $525 \mathrm{~km}$ long tributary of the Seine river, its source is located in the Langres Plateau in the Haute-Marne department (Fig. 1). The study is carried out on the upstream part of the river that is strongly sensitive to local precipitation and where flash floods (5 to $120 \mathrm{~m}^{3} . \mathrm{s}^{-1}$ within a 24h period in October 2006 at Condes) occur.
The landscape of the catchment is defined by forested plateaus, incised valleys and presents numerous limestone outcrops. Therefore the catchment area includes karstic areas and tributaries whose behaviour is highly nonlinear and thus difficult to forecast. As of today, the operational forecast relies on the integration of two sub-models on the Marne Amont and Marne Vallage areas (Fig. 1). These models are based on the mono-dimensional numerical code MASCARET for hydraulics describing the Saint-Venant (Shallow Water) equations and developed by EDF and CETMEF (Centre d'Etudes Techniques Maritimes Et Fluviales). They provide a satisfying water level signal, still discharges are usually underestimated and the maximum lead time for the forecast is 15 hours.

In order to extend the maximum lead time and benefit from measurements at Saucourt, the sub-models were merged into a global model extending from Villiers to Chamouilley and including the karstic areas of the Rognon. The upstream flows are specified at five upstream stations (Marnay, Louvières, Villiers, La Crête and Humberville). This global model underestimates the discharges of $50 \%$ on average over ten significant events for a representative event for Condes and Mussey observing stations. Indeed, the global model area is about $2250 \mathrm{~km}^{2}$ when the area controlled by the five upstream stations is only about $755 \mathrm{~km}^{2}$. Thus it appears that the modelling of lateral inflows, despite the lack of hydrologic rainfall-runoff model on the area, represents a key step towards the use of the global model for the Marne catchment. Five lateral inflows were then added to the model to represent the exsurgences of the Suize $\left(Q_{1}\right)$, the Seurre on the Rognon catchment $\left(\mathrm{Q}_{2}\right.$ and $\left.\mathrm{Q}_{3}\right)$, and tributaries upstream Musey $\left(\mathrm{Q}_{4}\right)$ and Chamouilley $\left(\mathrm{Q}_{5}\right)$. Given the homogeneous response of the catchment to an oceanic rainfall event, a water budget approach enables to describe a coherent, yet perfectible, behaviour of the catchment. Characteristic hydrographs of the catchment are used to represent the additional inflows with a multiplicative coefficient. The multiplicative coefficients $A_{i}$, with $i$ in $[1,5]$ and their statistics were identified over a batch calibration of 10 flood events and are presented in Table I. This estimation can be greatly improved with a sequential method that allows for temporal variability of the coefficients, essential for instance for summer and early autumn events when the karst behaviour is complex and the Villiers station may not be representative of the entire catchment's dynamics.

TABLE I. MULTIPLICATIVE CORRECTIVE COEFFICIENTS $\mathrm{A}_{i}$ FOR LATERAL INFLOWS AND STANDARD DEVIATIONS WITH i IN $[1,5]$

\begin{tabular}{|l|c|c|c|}
\hline $\mathbf{Q}_{\mathbf{i}}$ & Elementary hydrograph & $\mathbf{A}_{\mathbf{i}}$ & Std \\
\hline $\mathrm{Q}_{1}$ & Villiers & 3 & 0.8 \\
\hline $\mathrm{Q}_{2}$ & Villiers & 4 & 1.3 \\
\hline $\mathrm{Q}_{3}$ & Humberville & 3 & 1.8 \\
\hline $\mathrm{Q}_{4}$ & Villiers & 2.5 & 1.4 \\
\hline $\mathrm{Q}_{5}$ & Villiers & 5.5 & 2 \\
\hline
\end{tabular}



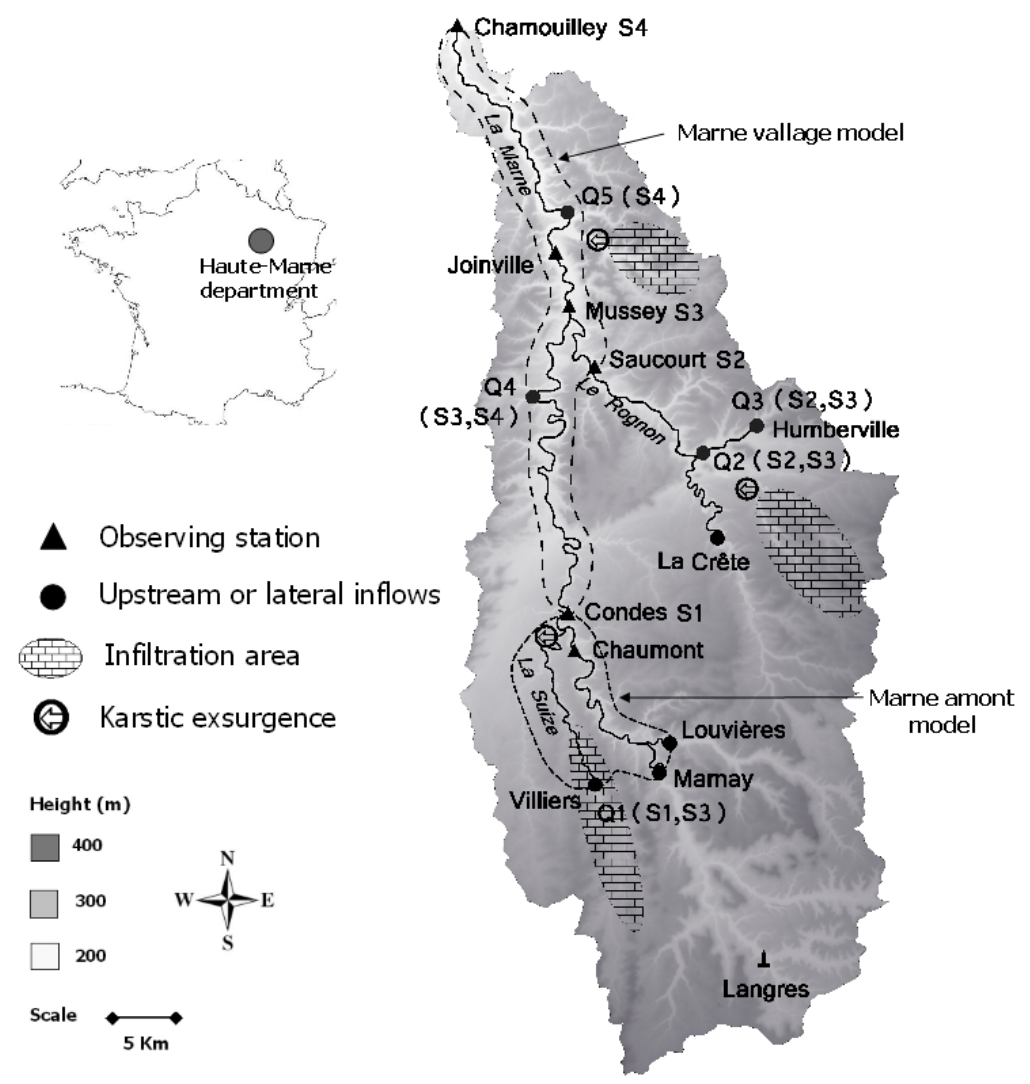

Figure 1. The Marne catchment, the sub-models are circled with dashed lines. The hydrological observing stations S1, S2, S3 and S4 are represented by black triangles. Lateral inflows Q1, Q2, Q3, Q4 and Q5 are represented by black dots and the observing stations on which they depend are in parentheses.

\section{SEQUENTIAL DATA ASSIMILATION METHOD}

\section{A. Extended Kalman Filter}

Data assimilation approaches aims at identifying the optimal estimate of the true value of an unknown variable $\mathbf{x}$ that includes, in this work, the set of corrective coefficients $A_{i}$ with $i$ in $[1,5]$. The a priori knowledge on these coefficients given in Table 1 describes the background vector $\mathbf{x}^{\hat{i}}$. The observation vector $y^{r}$ is composed of hourly discharge measurements, a conservative variable, at Condes, Saucourt, Mussey and Chamouilley (respectively denoted by $\mathrm{S}_{1}, \mathrm{~S}_{2}, \mathrm{~S}_{3}$ and $\mathrm{S}_{4}$ in Fig. 1). The analysis is performed on a sliding time window, over which the $A_{i}$ coefficients are assumed to be constant. Assuming that the background, the observation and the analysis are unbiased, the analysis vector $\mathbf{x}^{\mathrm{a}}$ for cycle $\mathrm{k}$ can be formulated as a correction to the background parameters:

$$
\mathbf{x}_{k}^{a} \quad \mathbf{x}_{\mathrm{k}}^{b} \mid \mathbf{K}_{\mathrm{k}}\left(\mathbf{y}_{\mathrm{k}}^{i} \quad H\left(\mathrm{x}_{\mathrm{k}}^{\mathrm{i}}\right)\right)
$$

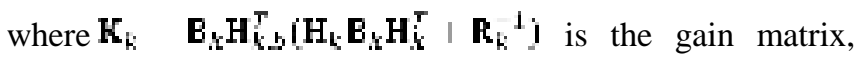
$\mathbf{B}_{\bar{k}}, \mathbf{R}_{\mathbf{k}}$ are the background and observation errors covariance matrices and $y_{i} \quad H_{k}\left(\mathbf{x}_{\mathrm{k}}\right)$ is the model equivalent of the observations, generated by the observation operator $H_{k}$.

The observation operator consists of two operations, the costliest of which is the non-linear integration of the hydraulics model given the upstream and lateral flow conditions over the assimilation window. The second operation is the selection of the calculated discharges at the observation points and at the observation times. $H_{\hat{k}}\left(x_{k}\right)$ represents the discharges at the observation points and times computed by MASCARET using the background parameters $\mathrm{A}_{\mathrm{i}}=1$.

The analysis is cycled over the period covering the entire flood event, thus allowing $A_{i}$ to vary between the cycles. For cycle $\mathrm{k}$, the observations over the first 8 hours (the reanalysis period) are used to estimate the optimal coefficients and a 24-hour forecast is carried out. Each of the five lateral inflows $\mathrm{Q}_{1}, \mathrm{Q}_{2}, \mathrm{Q}_{3}, \mathrm{Q}_{4}, \mathrm{Q}_{5}$ is controlled using downstream measurements from the hydrological observing station as described in Fig. 1; $\mathrm{Q}_{1}$ is controlled by Condes and Mussey, $\mathrm{Q}_{2}$ and $\mathrm{Q}_{3}$ are controlled by Saucourt and Mussey, $\mathrm{Q}_{4}$ is controlled by Mussey and Chamouilley and $\mathrm{Q}_{5}$ is controlled by Chamouilley only. A $5 \mathrm{~m}^{3} . \mathrm{s}^{-1}$ standard deviation error is assumed on the discharge measurements to account for errors in misadjustment of pressure tube and extrapolation of water level-discharge rating curves. The background error 
covariance is described by a diagonal matrix with the same standard deviation error on every $\mathrm{A}_{\mathrm{i}}$ estimated as the mean of those described in Table I.

\section{B. Local estimation of the observation operator}

The Jacobian matrix $\mathrm{H}_{k, v}$ is the tangent linear of the hydraulics model computed in the vicinity of $\mathbf{x}_{k}^{\hat{v}}$ as follows:

$$
H_{\mathrm{k}}\left(\mathrm{x}_{k}^{i} \mid \Delta \mathrm{x}\right) \quad H_{\mathrm{k}}\left(\mathrm{x}_{\hat{k}}\right) \mid \mathrm{H}_{\mathrm{L},} \Delta \mathrm{x}
$$

and $\mathbf{H}_{k, b} \mathbf{H}_{\mathrm{k},}^{\mathrm{i}}$, can be approximated using a finite differences scheme written as:

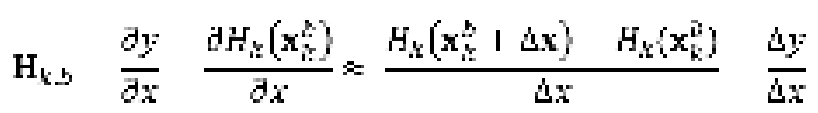

The local estimation of the tangent linear dynamics of the model with respect to the boundary conditions of the domain is a strong hypothesis. This method can be seen as an EKF algorithm without model errors (the model is considered as perfect). Since there is no propagation model for the parameters, the usual propagation steps of the KF algorithm are irrelevant here: the background error covariance matrix is invariant between the cycles.

The data assimilation algorithm was implemented using the OpenPALM dynamic coupler developed at CERFACS. This software was originally developed for the implementation of data assimilation in oceanography for use with the MERCATOR project. OpenPALM allows for the coupling of independent code components with a high level of modularity in the data exchanges and treatment while providing a straightforward parallelization environment [2]. The Parasol functionality in OpenPALM allows to automatically launch several executables of the same numerical code, in parallel. In this study, the Parasol functionality is used to launch the different integrations of MASCARET required for the finite difference scheme previously described. This allows for an efficient implementation of the DA algorithm with a reduced computational cost. For instance, when 5 inflows are corrected, at least 5 additional integrations of MASCARET are required to compute $\mathrm{H}_{\mathrm{k}, \mathrm{b}}$. Provided a large enough number of processors are available, these integrations can be achieved simultaneously.

\section{RESUlTS}

The benefits from the application of the sequential analysis over the 10 floods events for the Marne catchment are summarized in Table II presenting the Nash-Sutcliffe criteria computed with data assimilation (DA) and without (Free Run) at the maximum lead time for the forecast at each observing station. It was shown that the assimilation of discharge measurements allows for a significant improvement of the simulated discharges in re-analysis (not shown) and forecast mode; with an the average improvement of 0.91 at the maximum lead time.

TABLE II. NASH-SUTCLIFFE CRITERIA FOR FREE RUN AND DA SIMULATIONS AVERAGED OVER 10 FLOOD EVENTS OVER 2001-2010 AT MAXIMUM LEAD TIME FOR EACH OBSERVING STATION

\begin{tabular}{|l|c|c|c|c|c|}
\hline Observing station & S1 & S2 & Joinville & S3 & S4 \\
\hline Forecast lead time & $+6 \mathrm{~h}$ & $+10 \mathrm{~h}$ & $+13 \mathrm{~h}$ & $+12 \mathrm{~h}$ & $+21 \mathrm{~h}$ \\
\hline Free Run & 0.61 & -0.2 & 0.14 & 0.01 & -1.38 \\
\hline DA & 0.87 & 0.8 & 0.55 & 0.78 & 0.47 \\
\hline
\end{tabular}

For the major flood event in December 2010, the use of the DA procedure for real-time forecast would have improved both discharge peak forecasts of $15 \%$ as illustrated in Fig. 2 (only the first peak is shown). The discharges are presented on the left vertical axis and water levels are on the right vertical axis with solid thin and thick lines, respectively. Observations are represented by blue crossed curves, the Free Run 12 hour forecast by black solid curves and the analysis 12 hour forecast by red dashed curves. For the discharge and water level, the area between observation and Free Run is shaded in red when the model underestimates the signal and in blue when it overestimates the signal. The corrective coefficients for $\mathrm{Q}_{1}, \mathrm{Q}_{2}, \mathrm{Q}_{3}, \mathrm{Q}_{4}$ and $\mathrm{Q}_{5}$ represented in Fig. 3 are globally smaller than 1 when the Free Run overestimates the observed discharge and bigger than 1 where the Free Run underestimates the observed discharge. These values also depend on the sensitivity of the discharge at the observing station with respect to each $A_{i}$; this information is accounted for within the linearized observation operator $\mathrm{H}$.

Still, the assumption of a constant correction of the lateral inflows over a DA analysis cycle can lead to an inappropriate correction as displayed in Fig. 2 for Day 3. The 12-hour forecasted discharge at Day 3 , resulting from the DA procedure $\left(175 \mathrm{~m}^{3} . \mathrm{s}^{-1}\right.$ where the solid vertical line intersects the thick red dotted curve) is computed using the corrected inflows resulting from the assimilation of the difference between the Free Run and the observation during the 8-hour period in Fig. 2 represented in grey between the two thin vertical lines at Day $2+2 \mathrm{~h}$ and Day $2+10 \mathrm{~h}$. Over this period, the average discharge (thick curves) difference is bigger than that at Day 3, thus the DA procedure leads to an over correction of the discharge (an over decrease in this case): the solid red line at Day 3 is below the blue crossed line. To sum it up, if the model-observation error is not monotonous over the re-analysis and forecast period, the DA procedure can lead to an under or over correction. A possible leverage for this problem is to shorten the re-analysis period and thus allow for more temporal variability of the corrective coefficient.

Globally in Fig. 2, the water level is also significantly improved (thin curves), still the correction of the lateral inflows with assimilation of the discharge measurements 


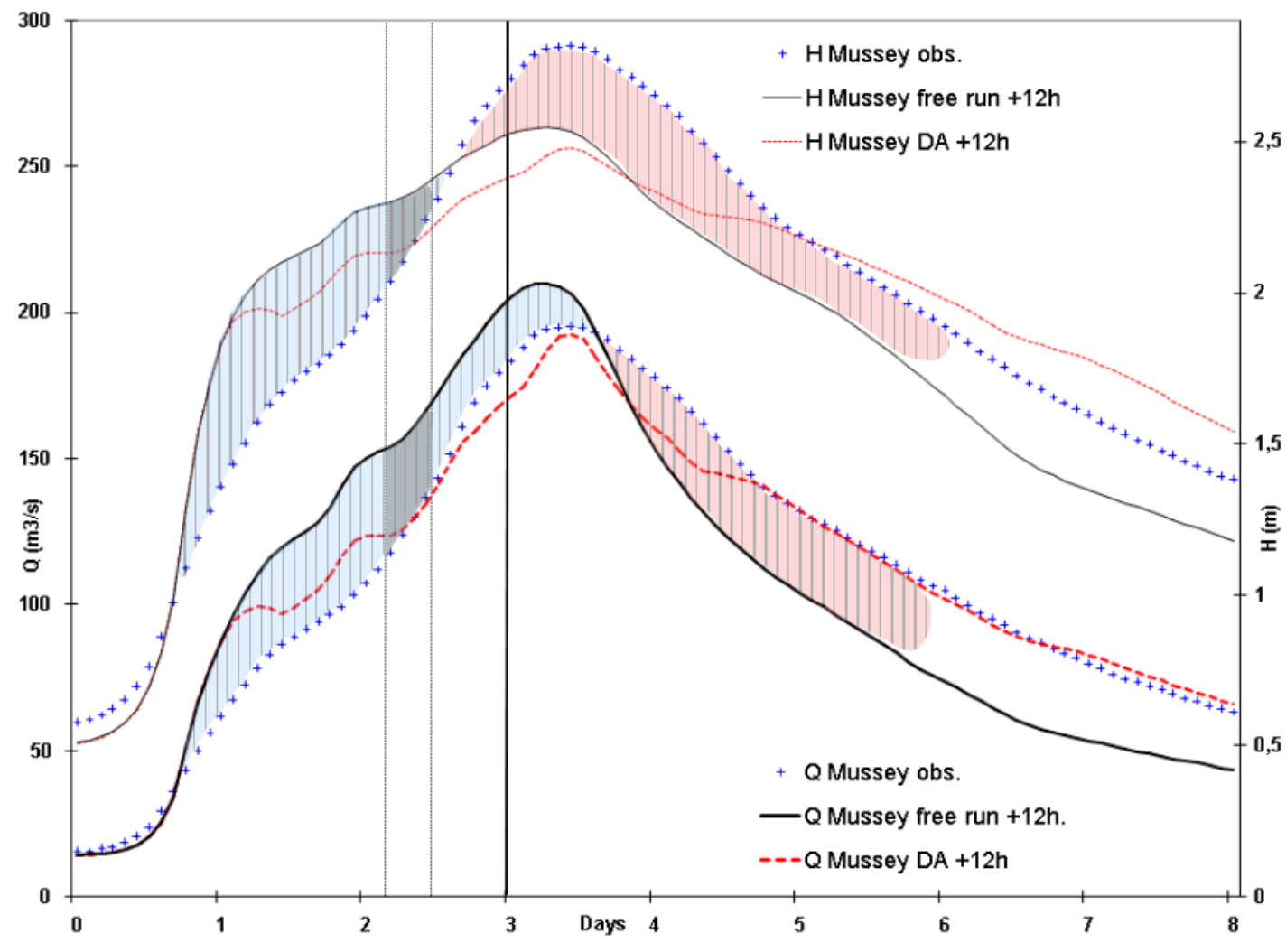

Figure 2. Discharge (thick curves) and water level (thin curves) at $+12 \mathrm{~h}$, December 2010 (Mussey): Observations (blue crossed curves), Free Run (black solid curves), DA analysis (red dashed curves).

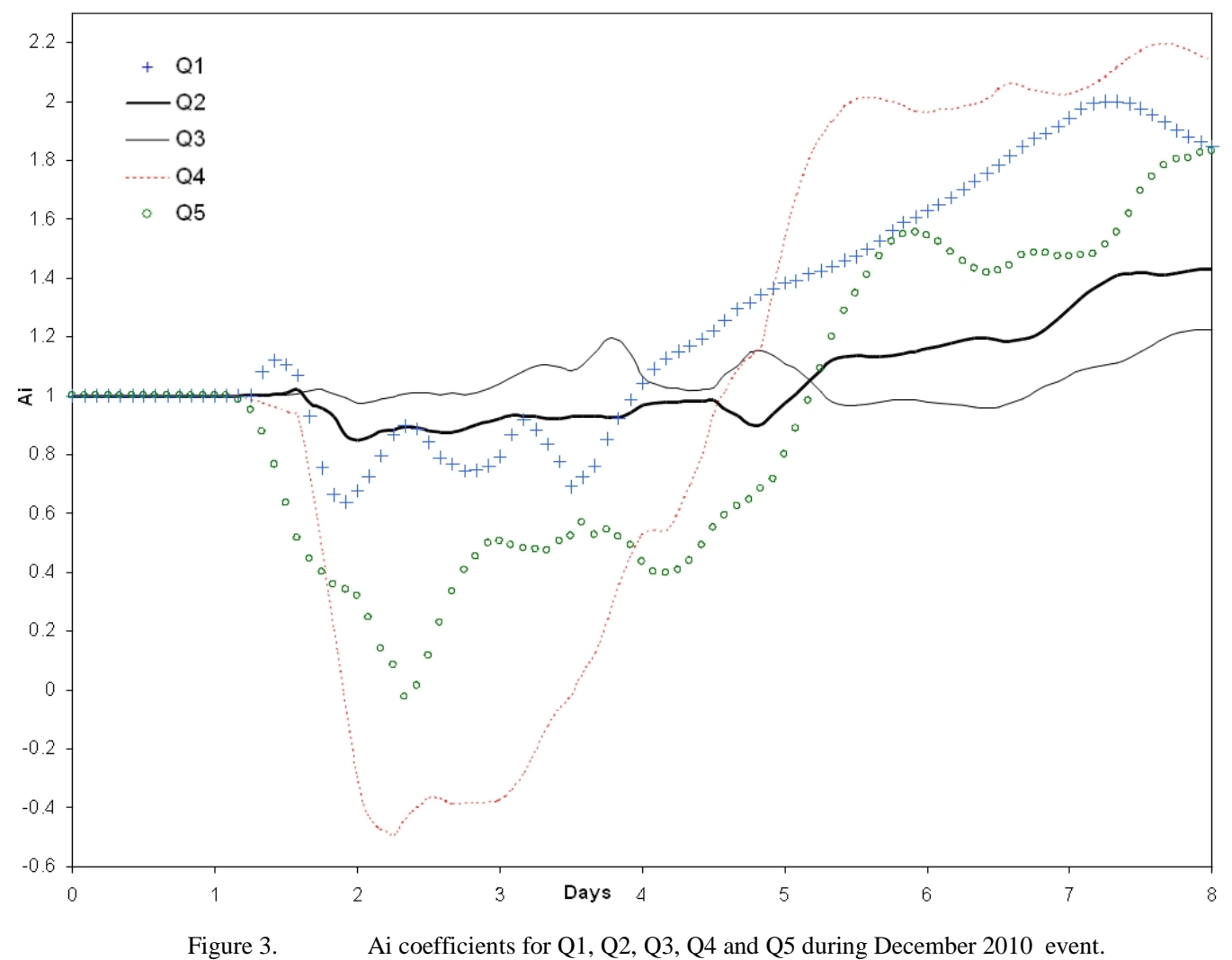


does not improve the water level peak simulation, it even degrades the first peak at Day $3+12 \mathrm{~h}$. Indeed, when the relation between water level and discharge in the model is not coherent with the relation between water level and discharge in the observation, the sign of model-observation error on discharge is different from the sign of the modelobservation error on water level. This is the case from Day 2.5 to Day 3.5; the Free Run simulation overestimates the discharge (blue area in Fig. 2) but underestimates the water level (red area in Fig. 2). Here, the DA correction tends to decrease the lateral inflow in order to decrease the simulated discharge, thus leading to the decrease of the simulated water level when the latter was already too small.

The friction coefficients (Ks) of the hydraulic model are mean values obtained from the calibration procedure using discharge data, over 10 flood events. The resulting values for the hydraulic section containing Mussey are 20 for the river channel and 13 for the flood plain. These values are potentially not well suited for high discharge events and might be responsible for a non-physical local relation between discharge and water level. To account for uncertainty in the topography and bathymetry, a local correction of the Ks coefficient at Mussey is applied (over a $200 \mathrm{~m}$ section downstream of the observing station). As illustrated in Fig. 3, a change in Ks allows to improve the simulated water level while the discharge is left unchanged by this local modification. Once the lateral inflows were corrected through the DA procedure, the simulated discharge is improved over the whole flood event, still the water level is overestimated (red areas in Fig. 3) from day 1 to 2.5 and 5 to 9 and underestimated at the flood peak (blue area in Fig. 3). An approximate calibration of the Ks coefficients is achieved to obtain the green curves in Fig. 3; the river channel and the flood plain coefficients are increased to 27 and 15 respectively over the overestimation periods and decreased to 16 and 9 over the underestimation period. The local correction of the Ks coefficients improves water level forecasts without changing discharges. Based on these results, ongoing work aims at including the Ks coefficients within the DA control vector of the previously described procedure.

As the correction of lateral inflows, Ks coefficients must be corrected sequentially as observations become available. The linear approximation of the relation between the Ks coefficients and the simulated hydraulic state should be investigated. Fig. 4 illustrates the nonlinear impact of the perturbation of the river channel $\mathrm{Ks}$ at the flood peak, at Mussey, around the reference value $\mathrm{Ks}=20$. For instance, a perturbation of 4 leads to a maximum discrepancy in water level of $2 \mathrm{~cm}$ with respect to the linear approximation computed for $\mathrm{dKs}=2$ (pink dashed line in Fig. 4). For a positive perturbation in Ks, the non-linearity is significantly smaller than for negative perturbations with a water level difference of $6 \mathrm{~cm}$ when the Ks is increased from 20 to 32 and up to $33 \mathrm{~cm}$ when the Ks is decreased from 20 to 8 . In order to keep the non-linearity impact small on the EKF analysis, the correction to the Ks coefficient should remain in a limited interval such as $[-5,5]$.

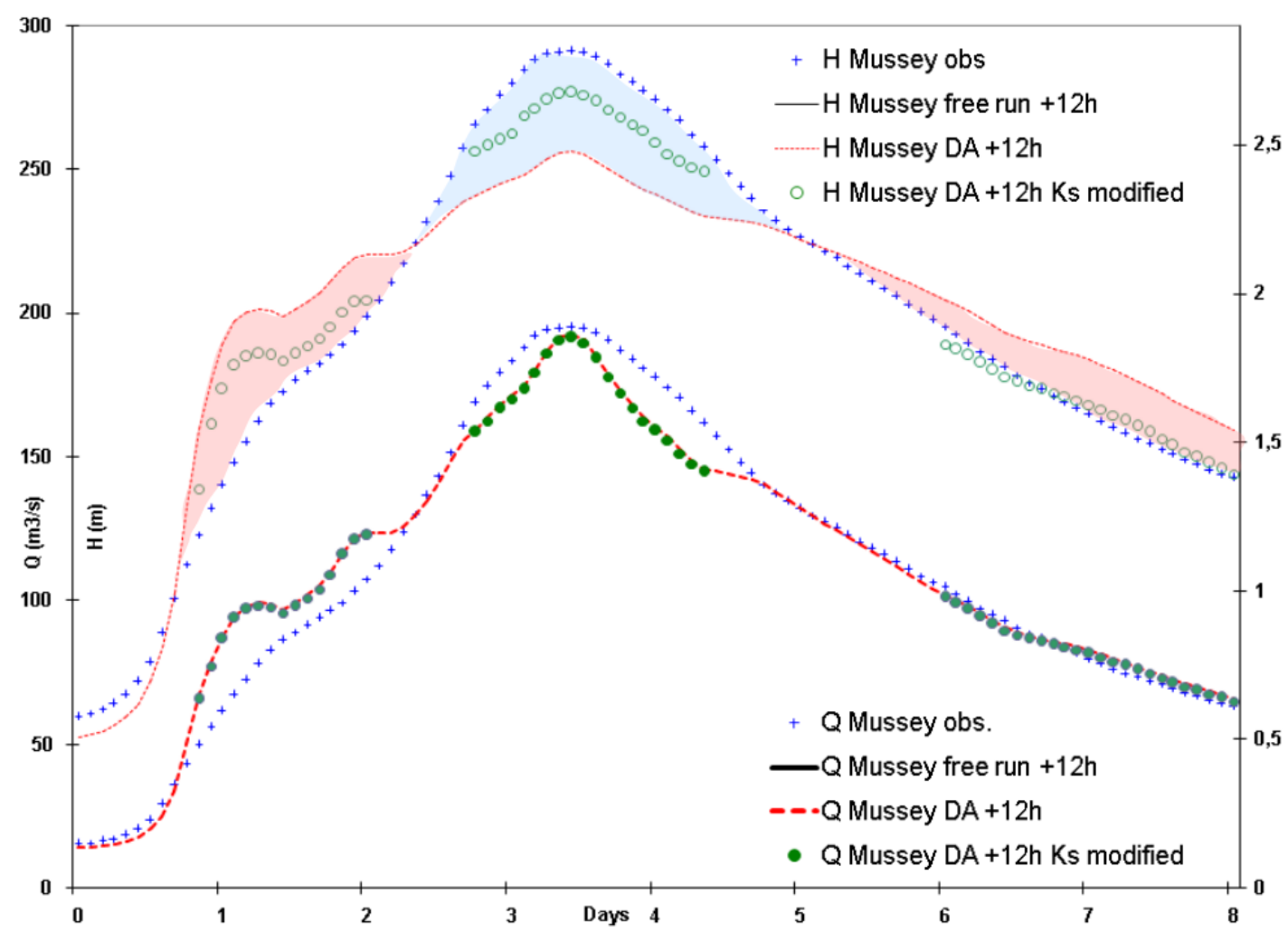

Figure 4. Discharge (thick curves) and water level (thin curves) at $+12 \mathrm{~h}$, December 2010 (Mussey): observations (blue crossed curves), DA analysis (red dasched curves) and DA analysis with modified Strickler coefficient (green dotted curves). 


\section{CONCLUSION}

The sequential assimilation of discharge measurements in real time mode was presented in this paper. The study focuses on the application of an Extended Kalman Filter (EKF) algorithm for the Marne catchment under the assumption that the relation between the lateral boundary conditions of the domain and the simulated discharge is fairly linear. It was shown that the estimation of the time varying contributions of the karstic areas and the neglected tributaries can be achieved. This leads to the improvement of the hydraulic state forecast at meaningful lead time for operational use. Since the method developed here is not catchment dependent, it was applied for other French catchments and it is currently being integrated in the realtime forecasting platform for operational use at SCHAPI. The reduced computational cost of the procedure is also a strong advantage. The extension of the control vector to model parameters such as the Strickler coefficients is one of the perspectives for further works as it will allow to correct the relation between water level and discharge within the model.

\section{REFERENCES}

[1] F. Bouttier and P. Courtier: Data assimilation concepts and methods, ECMWF Lecture Note, 1999.

[2] S. Buis, A. Piacentini, and D. Déclat: PALM: A computational framework for assembling high performance computing applications, Concurrency Computat.: Pract. Exper., 18(2), 247-262, 2006.

[3] G. Coccia and E. Todini: Recent developments in predictive uncertainty assessment based on the model conditional processor approach, Hydrol. Earth Syst. Sci., 7, 9219-9270; 2008b.

[4] C.M. Dechant and H. Moradkhani: Radiance data assimilation for operationnal snow and streamflow forecasting, Adv. Water Resour. Res., 34, 351-364, 2011a.

[5] G. Drogue, L. Pfister, T. Leviandier, A. El Idrissi, J.F. Iffly, P. Matgen, J. Humbert, and L. Hoffmann: Simulating the spatiotemporal variability of streamflow response to climatechange scenarios in a mesoscale basin, J. Hydrol., 293,255-269, 2004.

[6] Q. Duan, V. Gupta, S. Sorooshian, A.N. Rousseau and R. Turcotte: Preface in calibration of watershed Models, Water Sci. Appli. Ser., vol. 6; edited by Q. Duan et al., p. v, AGU, Washington, D. C, 2003.

[7] G. Evensen: Sequential data assimilation with a non linear quasigeostrophic model using Monte Carlo methods to forecast error statistics. J. Geophys. Res., 99:10143-62, 1994.

[8] A. Gelb: Applied optimal estimation, Cambridge Mass.: MIT Press, 1974.

[9] N. Goutal and F. Maurel: A finite volume solver for 1D shallow water equations applied in an actual river, Int. J. Numer. Meth. Fluids, 38(2), 1-19, 2002.
[10] N. Jean-Baptiste, P.O. Malaterre, C. Dorée and J. Sau: Data assimilation for real-time estimation of hydraulics states and unmeasured perturbations in a 1d hydrodynamic model. Math. and Computers in Simulation, 81, 2201-2214, 2009.

[11] Y. Liu and H.V. Gupta: Uncertainty in hydrologic modeling: Toward an integrated data assimilation framework, Water Res. Ser., 43, W07401, 2007.

[12] P.O. Malaterre, J.P. Baume and N. Jean-Baptiste: Calibration of open channel flow models: a system analysis and control engineering approach, SimHydro 2010.

[13] D. Maclaughlin and L. Townley: A reassessment of the groundwater inverse problem, Water Resour. Res., 32, 1131-1161, 1996.

[14] D. Maclaughlin: An integrated approach to hydrologic data assimilation: interpolation, smoothing, and filtering, Adv. Water Res., 25, 1275-1286, 2002.

[15] H. Moradkhani, S. Sorooshian, H. Gupta and P. Houser: Dual-state parameters estimation of hydrolocal models using ensemble Kalman filter. Adv. Water Res., 28, 135-147, 2005.

[16] R.H. Reichle: Data assimilation methods in the Earth sciences, Adv. Water Resour. 31; 1411-1418, 2008.

[17] S. Ricci, A. Piacentini, O. Thual, E. Le Pape and G. Jonville: Correction of upstream flow and hydraulics state with data assimilation in the context of flood forecasting, Hydrol. Earth Syst. Sci, 15, 1-21, 2011.

[18] G. Schumann, P.D. Bates, M.S. Horritt, P. Matgen and F. Pappenberger: Progress in integration of remote sensing derived flood extend and stage data and hydraulic models, Rev. Geophys., 47, 2009.

[19] D.J. Seo, L. Cajina, R. Corby and T. Howieson: Automatic state updating for operational streamflow forecasting via variational data assimilation, J. Hydrol., 367, 255-275, 2009.

[20] D.J. Seo, V. Koren and N. Cajina: Real-time variational assimilation of hydrologic and hydrometeorological data into operational hydrologic forecasting, J. Hydrometeorol., 4, 627-641, 2003.

[21] SOeS - CGDD (Service de l'Observation et des Statistiques Commissariat Général au Développement Durable): Croissance du nombre de logements en zones inondables, Le point sur, 6, Février 2009.

[22] G. Thirel, E. Martin, J.F. Mahfouf, S. Massart, S. Ricci and F. Habets: A past discharges assimilation system for ensemble streamflow forecasts over France, Part 1: Description and validation of the assimilation system, Hydrol. Earth Syst. Sci., 14, 1623-1637, 2010a.

[23] G. Thirel, E. Martin, J.F. Mahfouf, S. Massart, S. Ricci, F. Regimbeau and F. Habets: A past discharges assimilation system for ensemble streamflow forecasts over France, Part 2: Impact on the streamflow forecasts, Hydrol. Earth Syst. Sci., 14, 1639-1653, 2010b.

[24] J.A. Vrugt, H.V. Gupta, W. Bouten and S. Sorooshian: A shuffled complex evolution metropolis algorithm for optimization and uncertainty assessment of hydrological parameters. Water Resour. Res., 39(8), 1-14, 2003.

[25] A.H. Weerts and Y. Liu: Advances in data assimilation for operational hydrologic forecasting, Eos Trans. AGU, 92, 2011. 